this section is so subjective that the arguments supporting prenatal diagnosis and selective termination of affected pregnancies are merely posed, then immediately dismissed. Any discussion is so biassed as hardly to merit being described as such; rather, the book constitutes a constant and unashamed diatribe against the use of prenatal diagnosis in any form other than as a therapeutic means of identifying treatable disorders.

It is unfortunate that the book is published at a time when the abortion laws in this country are undergoing radical, liberal revision, since a discussion of the imminent changes to the 1967 Act has not been included. Indeed, the author's early remark that it is ... quite possible that before the end of this century we shall see many of the more liberal laws (concerning abortion) repealed or amended restrictively' is, in retrospect, rather far from the truth. One might be forgiven for construing it as wishful thinking.

VIRGINIA N BOLTON Senior Embryologist/Honorary Lecturer, Assisted Conception Unit, Department of Obstetrics and Gynaecology, King's College School of Medicine and Dentistry, University of London.

\section{Loss and Bereavement}

Bridget Cook and Shelagh G Phillips, 90 pages, London, £6.50, Austen Cornish Publishers Limited in association with The Lisa Sainsbury Foundation, 1988.

It is understandable that a journal of medical ethics should select for review, publications with an obvious focus on ethical issues. Although this book does not lay claim to such a focus, I am pleased that the attention of readers of this journal is being directed to it. Of course, any text dealing with human crises must encompass ethical issues or dilemmas, either explicitly or implicitly. Professional carers specifically, confronted with human beings in grief for whatever reasons, must be aware of the ethical foundations on which the caring process is based. The two authors clearly demonstrate such awareness. Their sensitivity to the bereaved person's rights, dignity and individuality permeates the text throughout.
The book makes an important contribution to the understanding of loss in its widest sense to include not only death, but also events like the loss of status, of a relationship, of a faculty or of material possessions. The reader is taken right through the complex process of the loss experience and the subsequent grief. Available literature and the authors' personal experiences are used as signposts. The resulting volume achieves an admirable balance between generalisable practical guidelines and most careful attention to individual needs and problems. For example, two flow charts, taken from Which Books 1986 simplify the practical arrangements after death and in relation to the funeral, which bereaved people often find so bewildering. They are excellent general guidelines. The constant emphasis on the need for individual assessment as a basis for appropriate after-care demonstrates the importance of individual differences.

A reading list for the bereaved and a list of useful addresses are added benefits.

Although there seems to be a distinct decrease in the taboo surrounding death in Western society, there remains a good deal of confusion, anxiety and fear. This clear, informative, sensitive and well presented publication provides valuable help for those who attempt to care for bereaved persons.

LISBETH HOCKEY Research Consultant, Flat 2, Silverknowes House, 1 Silverknowes Road, Edinburgh 4

\section{Ethics and Human Values in Family Planning}

Z Bankowski, J Bazelatto, AM Capron, 308 pages, Geneva, 20 SFR (UK price unstated), Council for International Organisations of Medical Sciences (CIOMS), 1989

This book is derived from the XXII CIOMS Conference held in Bangkok in 1988. However, in comparison with many similar volumes of proceedings from multi-disciplinary conferences its layout has been arranged to state first, an objective, second, the material for deliberation and finally such consensus as was derived. The material is not laid out succinctly and in some respects this is a difficult volume to follow. However, once the reader has begun to find his or her way through th contributions it does become a very? readable and very original book.

The phrase 'family planning? encompasses a wide range of activitie in reproductive medicine includin abortion, sterilisation, treatment ande research into infertility and prenata巾 diagnosis - the whole field of reproductive medicine. The books commences with full coverage in the first six pages of the remarks made at the opening of the conference. Thes $\vec{E}$ serve to underline the WHO's concern with the issues facing family planning worldwide and the need to find common ground amid the wide range o $\vec{G}$ medical, sociological, philosophicalis religious and political factors influencing the provision of reproductive health care globally These remarks are echoed in the keynote address by $\mathrm{Dr}$ Anne MaclarenApart from re-stating the conference objective, this contribution is an excellent introduction to the materian discussed elsewhere. Two subsequen sections of the book examine from two different perspectives, the spectrungoto issues under consideration. First, foug chapters deal with ethical, cultural and religious, scientific and losab perspectives. Each of these is written $b$ acknowledged experts in their own fiel who have chosen language easilit understandable by colleagues in otheg disciplines. The following section examines the same complex array of issues from a regional point of view? with chapters dealing with Africa, Latio America, Europe and North America, Asia and Oceania and finally the Middle. East. Most of these concentrate on historical and demographical factors that modify or are modified by cultury. and religious settings, an aspect of the problem that is often overlooked in less internationally orientated works. Sucb consensus as was derived is enumerated, first in the reports of sis working groups that dealt with family. planning and health services, familos planning methods, infertility, prenatal diagnosis and research in fertility and infertility. Further consolidation of views is given in a series of reflections ow the conference from the perspectives of an ethicist, a lawyer, a bio-medicat scientist, a social scientist, a health policy maker and a lay person. In view of the thoroughness with which this topic is explored, I can thoroughlo recommend this book to anyone involved in reproductive medicing either internationally or in any setting that could be vaguely construed as multicultural. 
If any single message is conveyed by this work it is that the mere existence of the immense plurality of opinion in this field actually denies the possibility of absolute truths. If any exception is seen it is the need to maintain the patient's autonomy of choice, based on sound information.

DAVID R BROMHAM Senior Lecturer and Honorary Consultant in Obstetrics and Gynaecology, Department of Obstetrics and Gynaecology,

St James's Hospital, Leeds

\section{Medical Law: Text and Materials}

Ian Kennedy and Andrew Grubb, 1224 pages, London, $£ 30.00$, Butterworths, 1989

Whether or not they have been entirely happy about the process, the courts have been required increasingly frequently to pronounce on matters touching on medical ethics. In decisions on a wide range of subjects, judges have been obliged to decide not just what the legal rule is, but what is the morally acceptable response to a particular problem. This has given rise to a body of jurisprudence which cannot be ignored by those with an interest in the subject. One could not, for example, discuss the British response to the issue of teenage access to contraception fully without a nod in the direction of the Gillick decision. Nor would a debate on attitudes in the United Kingdom to the sterilisation of the mentally handicapped be complete without some reference to the several decisions which the British courts have now handed down on this morally difficult matter.

In this weighty (over twelve hundred pages) collection of medico-legal materials, Ian Kennedy and Andrew Grubb have burrowed their way through a vast mountain of court decisions, legislation and legal commentary, to come up with a compilation of the legal response to both old and new medical problems. The value of this enterprise to the lawyer is self-evident, particularly in an area of the law which has spawned a notoriously large literature. But what is there here for the non-lawyer - for the broad constituency of those interested in medical ethics?

There is a great deal. From the very beginning of their exhaustive enterprise, the authors stress the interrelationship of law and ethics in this area. The law is seen as one way of resolving certain immediate uncertainties or disputes, but the ethical dimension of what might otherwise be mistaken for a narrow legal issue is not ignored. Then, in each of the topics subsequently addressed, ethical issues are raised and discussed. But this of itself is probably no reason for the book to be read by the reader interested in medical ethics; the ethical material excerpted is usually from familiar sources (the President's Commission, Beauchamp and Childress etc). The real attraction for such a reader will be the legal treatment itself. Many reports are difficult to get hold of, as may also be the case with statutes or the reports of government bodies. This book reproduces the relevant section of the judgements or the legislation, thus providing ready access to the essence of the legal problem.

This is particularly useful in relation to the American court decisions reproduced here. Although Kennedy and Grubb concentrate on English law, the decisions of other common law countries, including those of the United States, are quoted where appropriate. Thus, for example, there are reproduced here some of the more important American decisions on the cessation of treatment in hopeless cases, an area of the law on which there is very little British authority (apart from the decision in one or two cases involving the treatment of mentally handicapped children). For those interested in the problem of the excessive prolongation of life, the facts of these cases - and the legal response - give considerable flesh to an issue which might otherwise remain a theoretical debate.

There is now a reasonable choice of general textbooks on medico-legal issues available to the non-legal reader. This book takes this process further, in providing such a reader with direct and helpfully guided access to the raw materials of the legal debate. For this reason, it is of immense value and interest.

ALEXANDER MCCALL SMITH Senior Lecturer, Faculty of Law, University of Edinburgh

\section{The Misfortunes of Others: End-stage Renal Disease in the United Kingdom}

\author{
Thomas Halper, 219 pages, \\ Cambridge, $£ 25.00$, Cambridge \\ University Press, 1989.
}

I have experienced great difficulties in reviewing this book. This is partly because I am, as an economist, unclear why the book was written, or from what specific perspective, since nowhere is the author or his background described.

The book covers various considerations regarding end-stage renal disease in the United Kingdom. It presents in chapter 1 some useful comparative data concerning renal dialysis and transplantation in the UK vis-a-vis such activities in other countries. Chapter 2 deals with what is called 'macro allocation', essentially looking at resource allocation under the UK National Health Service; chapter 3 concerns 'micro allocation' ie decisionmaking with respect to resource allocation in the specific context of endstage renal disease; and the fourth and final chapter offers what are called 'some premature conclusions'.

Having agreed to review this book, I then found myself wading through too many platitudes, together with contradictory statements and nuances, never quite knowing where the author sought to lead me.

A couple of comments may exemplify why I am so unhappy with this book. On page 120 the author states apparently in some degree of horror or, at a minimum, distaste - 'a nephrologist who was interviewed volunteered that he and his colleagues prescribed lower dosages of some drugs in order to save money'. But so what? Why is saving money - which might be better used elsewhere - seemingly so wrong?

On page 117, the author states: 'It is true, of course, that treating only patients with the best prognoses is the most effective use of scarce resources; more patients per unit of resources can be treated in this way than by any alternative approach. Some observers might retort, however, that efficiency is not the highest value. Ought dialyzing ten Charles Mansons be preferred to dialyzing five Mozarts (or five of my saintly uncles) merely because the Mansons have better prognoses?'

There are several problems with this. First it is not the case that the statement 'treating only patients with the best 